\title{
State of the art in the care of the depressed patient
}

\author{
Abdul-Monaf $\mathrm{H}$. Al-Jadiry \\ From the Department of Medicine, Medical Faculty, University of Jordan. \\ Correspondence: Abdul-Monaf H. Al-Jadiry. Professor of Psychiatry, Department of Medicine, Medical Faculty, University of \\ Jordan, Amman, Jordan. Email: aljadiryamh@yahoo.com. \\ (Ann. Coll. Med. Mosul 2013; 39 (1): 1-6). \\ Received: $13^{\text {th }}$ May 2012; Accepted: $6^{\text {th }}$ Nov. 2012.
}

\section{ABSTRACT}

Background: Depression continues to be a major cause of morbidity and mortality. Depression is a common debilitating illness that can happen to anyone, at any age, and to people of any race or ethnic group. Females are more vulnerable than males; one out of four women may have depression sometime during their lifetime. Despite the wide range of people who suffer from this serious disorder and the associated high risk of death from suicide, only 20 percent are currently receiving treatment. Moreover, it is well recognized that depression greatly contributes to fatality associated with heart disease. The 1990 Global Burden of Disease Study ranked depression as the fourth leading disease burden worldwide as measured by life-years lost to disability, and it is projected to be ranked as the second leading disease burden by the year 2020. In light of these statistics, there is a clear need to address the impact of this condition and to develop new methods to adequately diagnose and treat those who suffer.

Objective: The objective of this paper is to highlight recent developments regarding treatment and care of the depressed patient.

Method: A review of recent literature on the neurobiology of depressive disorder, and its reflection on the care and treatment of the depressed patient formed the matrix for this paper.

Neurobiology of depression: Evidence from neuroscience, genetics, and clinical investigation demonstrate that depression is a disorder of the brain. Modern brain imaging technologies are revealing that in depression, neural circuits responsible for the regulation of moods, thinking, sleep, appetite, and behavior fail to function properly, and that critical neurotransmitters are perhaps out of balance. Genetics research indicates that vulnerability to depression results from the influence of multiple genes acting together with environmental factors. Studies of brain chemistry and of mechanisms of action of antidepressant medications continue to inform the development of new and better medical and psychotherapy treatments. $S_{T A R}^{*} D$, a large study funded by the National Institutes for Mental Health, found that less than half of patients got completely well after a single antidepressant was taken, and although more patients got well once they were switched to another medicine, the proportion of those who got better decreased each time a person had to switch to another medication.

Treatment of depression: Recent advances in treatment have occurred for patients with mood disorders, these include: pharmacotherapy, combined psychotherapy pharmacotherapy, and novel physical therapies. The focus of new drug development reflects a shift from serotonin specificity to combine or specific noradrenergic activity. The efficacy of sequencing cognitive therapy after anti-depressant treatment in patients who were partially remitted was examined recently by Paykel and colleagues. The cumulative relapse rate was reduced significantly from $47 \%$ in the clinical management control group to $29 \%$ in the group that received 16 sessions of cognitive therapy.

Conclusion: Improved recognition, treatment, and prevention of depression are critical public health priorities. The administration of combination of treatment interventions and dual reuptake inhibitors are likely to ensure early response and prevention of relapse. Recovery of function ought to be the target of any treatment plan. 


\section{الجديد في العناية بالمريض المصاب بالكآبة}

الخلاصة

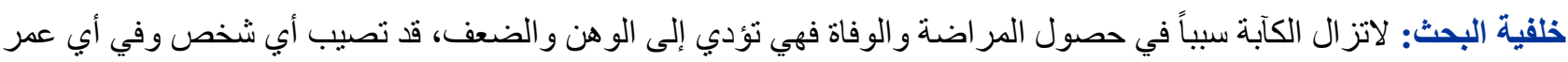

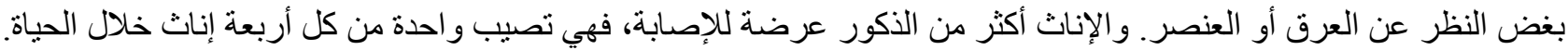

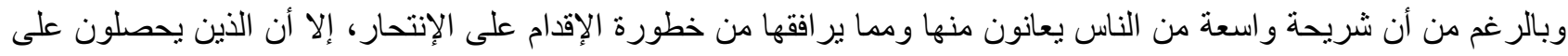

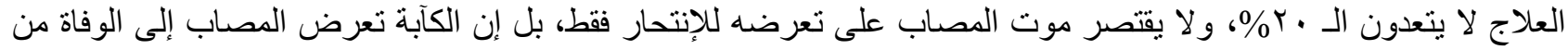

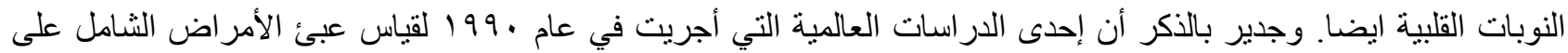

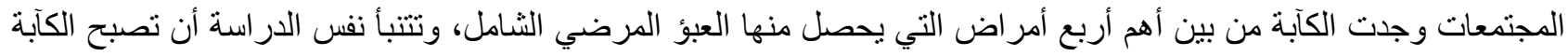

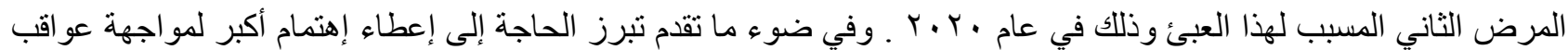

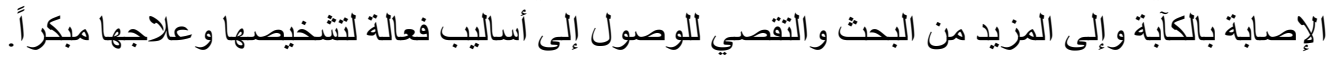

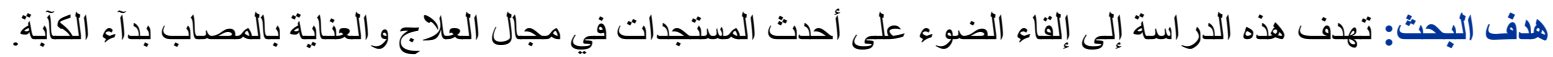

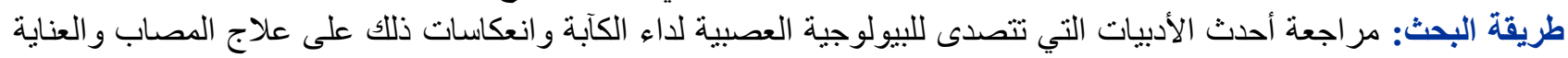
البيولوجية العصبية للكآبة: المؤشرات البحثية في العلوم العصبية والجينية والتحريات السريرية تدل على أن الكآبة اضطراب

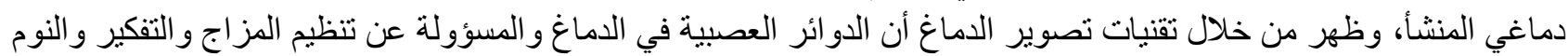

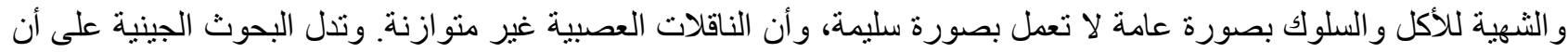

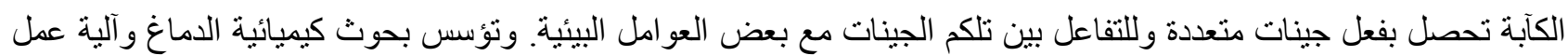
مضادات الكآبة إلى إكتشاف عقاقير علاجية و علاجات نفسية أفضل. وأن دراسة STAR"D المشهورة الممولة من المعاهد القومية

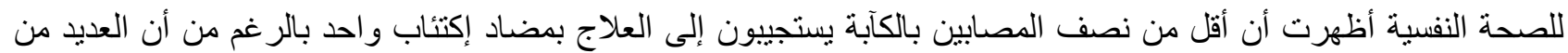

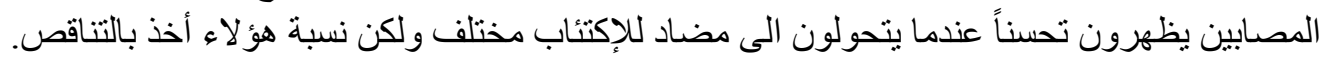

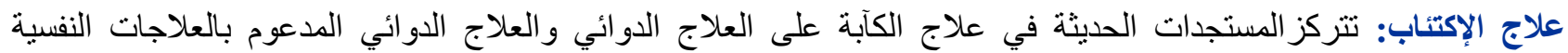

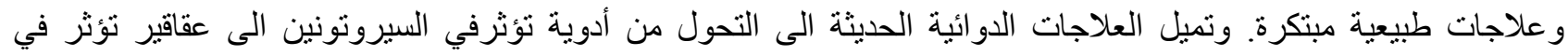
السيرونونين و النور أدرينالين مجتمعا. هذا وقد بحث Paykel وزملائه في دور العلاج المعرفي المضاف إلى علاج الميات المصابين

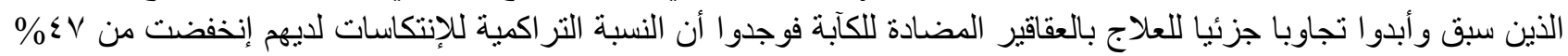

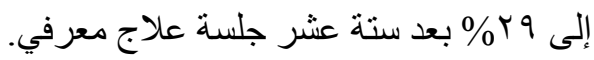

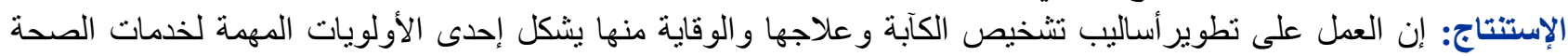

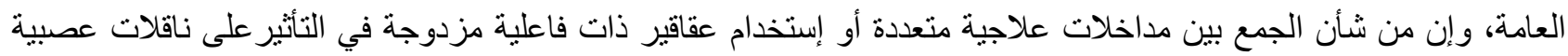

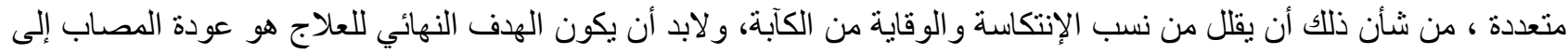

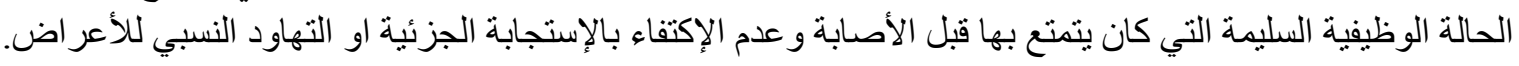

$\mathrm{D}$ epression is a brain disease associated with widespread impairment in biopsychosocial functioning, and continues to be a major cause of morbidity and mortality. Depression is a common debilitating illness that can happen to anyone, at any age, and to people of any race or ethnic group. Females are more vulnerable than males; one out four women may have depression sometime during their lifetime. Despite the wide range of people who suffer from this serious disorder and the associated high risk of death from suicide, only 20 percent are currently receiving treatment.
Moreover, it is well recognized that depression greatly contributes to fatality associated with heart disease. The 1990 Global Burden of Disease Study ranked depression as the fourth leading disease burden worldwide as measured by lifeyears lost to disability, and it is projected to be ranked as the second leading disease burden by the year 2020 after ischemic heart disease, and the first leading disease burden by the year 2030 . In light of these data, there is a clear need to develop new methods to adequately diagnose and 
treat those who are overwhelmed by depressive disorders.

Evidence from neuroscience indicated that depression is a disorder of the brain. Modern brain imaging technologies are revealing that, in depression, neural circuits responsible for the regulation of moods, thinking, sleep, appetite, and behavior fail to function properly, and that critical neurotransmitters are perhaps out of balance. Genetics research indicates that vulnerability to depression results from the influence of multiple genes acting together with environmental factors. Studies of brain chemistry and of mechanisms of action of antidepressant medications continue to inform the development of new and better medical and psychotherapy treatments. "STAR* D", a large study funded by the National Institutes for Mental Health, found that less than half of patients got completely well after a single antidepressant was taken, and although more patients got well once they were switched to another medicine, the proportion of those who got better decreased each time a person had to switch to another medication $^{(1)}$.

Recent advances in treatment have occurred for patients with mood disorders, these include: pharmacotherapy, combined psychotherapy pharmacotherapy, and novel physical therapies. The focus of new drug development reflects a shift from serotonin specificity to combine or specific noradrenergic activity. The efficacy of sequencing cognitive therapy after anti-depressant treatment in patients who were partially remitted was examined recently by Paykel and colleagues. The cumulative relapse rate was reduced significantly from $47 \%$ in the clinical management control group to $29 \%$ in the group that received 16 sessions of cognitive therapy.

Improved recognition, treatment, and prevention of depression are critical public health priorities. Recent years have been associated with significant advances in the understanding of depressive disorders with reflections on the nature and quality of care offered to the depressed patient. These advances occurred in perspectives of neurobiology of depression at neuroanatomical and neuro- molecular levels. The objective of this paper is to highlight recent developments in the neurobiology and treatment of depression.

\section{Prevalence of depressive disorders}

Epidemiological studies have consistently shown that depression is one of the most prevalent lifetime psychiatric disorder, and that major depressive disorder (MDD) remains one of the most frequently seen psychiatric illnesses in primary care settings ${ }^{(2)}$. Lifetime prevalence varies widely, from $3 \%$ in Japan to $17 \%$ in the US. In most countries the number of people who would suffer from depression during their lives falls within an $8-12 \%$ range $^{(3,4)}$. The Iraqi Mental Health survey reported a lifetime prevalence of $7.82 \%{ }^{(5)}$. Population studies have consistently shown major depression to be about twice as common in women as in men, although it is unclear why this is so, and whether factors unaccounted for are contributing to this. People are most likely to suffer their first depressive episode between the ages of 30 and 40 , and there is a second, smaller peak of incidence between ages 50 and $60^{(6)}$. The risk of major depression is increased with neurological conditions such as stroke, Parkinson's disease or multiple sclerosis, and during the first year after childbirth $^{(7)}$. It is also more common after cardiovascular illnesses, and is related more to a poor outcome than to a better one ${ }^{(8,9)}$.

\section{Course of depressive disorders}

MDD is a recurrent episodic disorder. In a 15-year follow up of a prospective study of a sample of 380 patients with MDD episode, $73 \%$ experienced a recurrent episode ${ }^{(10)}$. Each subsequent episode increases the probability of further episodes ${ }^{(11)}$. The STAR*D project revealed that $74 \%$ of 1500 patients treated experienced more than one episode ${ }^{(1)}$.

Several factors are thought to contribute for the neurobiological vulnerabilities underlying recurrence of MDD, these include:

- Family history of depressive illness and an earlier onset of first episode ${ }^{(1)}$.

- The process of "kindling", in which the threshold for the impact of stressful life events becomes lowered ${ }^{(12)}$.

- Number of previous episodes of MDD ${ }^{(13)}$.

- High genetic loading ${ }^{(14)}$.

- Early childhood adversities ${ }^{(15)}$.

- Neurobiological changes associated with depressive illness ${ }^{(1)}$. 
Recovery from depression is determined by the duration of the depressive episode. Patients whose depressive episodes persisted for more than 5 years experienced much lower recovery rate than patients whose episodes lasted less than one year ${ }^{(16,17)}$. Thus, the golden treatment goal has been shifted from response to remission and recovery.

\section{Recent developments in the neurobiology of depression}

Advances in neuroimaging and other techniques, and diagnostic aids facilitated understanding neuroanatomical and functional change underlying depressive disorders. Abnormalities in many prefrontal and limbic structures, and their interconnected circuits have been associated with mood regulation; these include: the ventromedial prefrontal cortex (VMPFC), lateral orbital prefrontal cortex (LOPFC), dorsolateral prefrontal cortex (DLPFC), anterior cingulated cortex (ACC), ventral striatum plus nucleus accumbens ( $\mathrm{nAC}$ ), amygdala and hippocampus. These structures function as an integrated circuit implicated, in addition to mood regulation, in learning, memory, pain mediation, aggression, sexual function, eating behaviour, risk assessment, modulation of of maladaptive and preservative affective states, maintenance of executive functions, effortful sustained attention and working memory processes ${ }^{(18)}$.

Regional blood-flow studies showed hyperactivity in the VMPFC and LOPFC (associated with increased sensitivity to pain, anxiety, depressive ruminations and tension) and hypoactivity in the DLFPC (associated with psychomotor retardation, apathy, and deficits in working memory and attention).

A decrement in the communication between the amygdala and ACC region was found in $\mathrm{AMRI}$ studies of neuroconnectivity, consequently this abnormality lead to a failure of the inhibitory function of the ACC on emotional regulation and further motivational and affective disruption ${ }^{(19,20)}$.

The hippocampal volume was found to be reduced in patients (with greater decrement in the right hippocampal volume) in patients with MDD in imaging studies ${ }^{(21)}$. Genomic imaging studies have shown associations between hippocampal volume and specific genes that are mediated in mood disorders ${ }^{(22,23)}$. Moreover, morphological differences in the hippocampus may be a predisposing factor in MDD; however, structural changes can also accumulate in the course of the disease and thereby create an obstacle to full recovery.

The key findings at the neuromolecular level include:

1. Cortisol (stress hormone) has been found consistently elevated resulting in impairment in neuroplasticity and cellular resistance ${ }^{(24)}$.

2. Imbalance between glucocorticoid and mineralcorticoid receptors in MDD resulting in neuronal damage in the hippocampus ${ }^{(25)}$.

3. Stress results in release of glucocorticoids and corticotrophin releasing hormones $(\mathrm{CRH})$, and proinflammatory cytokines. Depression disrupts serotonin, norepinephrine and dopamine leading to impairment in the regulatory feedback loops that "turn off" the stress response. Sympathetic activity contributes to immune activation and release of proinflammatory cytokines. The latter further interfere with monoaminergic and neurotrophic signaling and may diminish central corticosteroid receptor sensitivity leading to disruption of feedback control ${ }^{(26)}$.

4. Levels of BDNF (Brain derived neurotrophic factor) have been found to be significantly lower in untreated patients with MDD compared with treated patients or healthy controls ${ }^{(27)}$. BDNF is a dendritic protein involved in cell maintenance, plasticity, growth and death. When BDNF interacts with tyrosine receptors kinase receptors, it promotes cellular resilience and long-term potentiation. BDNF dysregulation occurs under conditions of chronic stress and depression.

5. The "neurotrophic hypothesis" of the pathogenesis of major depression states that stress and genetic vulnerability elevate glucocorticoid steroids and alter cellular plasticity via down regulation of growth factors and receptor sensitivity ${ }^{(28)}$. The reduction in growth factors such as BDNF, impacts negatively on the structural and functional processes within the limbic system, especially the hippocampus. Furthermore, chronic and recurrent MDD may result in subsequent atrophy and further disruption in neuro circuity. The implication of this hypothesis, recovery and remission of MDD would be dependent 
upon a reversal of these processes, such as increase in BDNF levels.

6. Recent findings from research on the monoamine theory revealed that chronic treatment with monoamine reuptake inhibitors increases activation of cyclic adenosine 3-4 monophosphatase (cAMP) which in turn stimulates protein kinase $A$; activation of this protein enzyme regulates target genes leading to an increase in BDNF synthesis ${ }^{(29)}$. Moreover, response to antidepressants has been associated with re-establishment of cortical activity and normalization in the amygdala and ACC, and failure in response was associated with elevation of proinflammatory cytokines ${ }^{(30,31,32)}$. Restoration of the neurobiological regulation in MDD via neurotrophic factors and neurogenesis appears to be a common factor across various effective treatments for MDD, including pharmacological, psychological and somatic treatments, such as diet and exercise ${ }^{(33)}$.

\section{Treatment of the depressed patient}

The neurobiological hypothesis has several implications, these include:

1. Treatment intervention of MDD should be started early and focused on achieving rapid remission and recovery. Longitudinal studies have shown that one of the best predictors of remission status at 2 years was response to acute treatment, i.e. initial 6 weeks ${ }^{(34,35)}$.

2. Early response to treatment can be augmented by the use of therapeutic interventions which activates multiple aminergic systems. Amongst these interventions is the use of combination treatments or dual reuptake inhibitors ${ }^{(36)}$.

3. Dual reuptake inhibitors targeting both serotonin and norepinephrine had been shown to be associated with improving not only the core features of depression, but also the correlated physical symptoms, such as pain. These symptoms increase the illness burden and impair the ability to attain remission ${ }^{(37,38)}$. Patients with MDD who experienced more than $50 \%$ remission in pain were more likely to achieve remission than patients whose pain reduction was less than $50 \%{ }^{(39)}$. Furthermore, patients who had attained partial remission were more likely to relapse $(67.5 \%)$ than patients who had obtained full remission ${ }^{(40)}$.

\section{CONCLUSIONS}

Major depression is a common mood disorder that affects a substantial number of people in any population. Neurobiological abnormalities underlie both the manifestations and disease burden of MDD. Recurrence and chronicity of MDD negatively impact the course of the disorder and outcome of treatment. The administration of combination of treatment interventions and dual reuptake inhibitors are likely to ensure early response and prevention of relapse. Recovery of function ought to be the target of any treatment plan.

\section{REFERENCES}

1. Hollon SD, Shelton RC, Wisniewski S, et al. Presenting characteristics of depressed outpatients as a function of recurrence: preliminary findings from the STAR $^{\star}$ D clinical trial. J Psychiatr Res. 2006;40:59-69.

2. Remick RA. Diagnosis and management of depression in primary care: a clinical update and review. Can Med Assoc J. 2002;167:1253-60

3. Andrade L, Caraveo-A. Epidemiology of major depressive disorders: Results from the International Consortium of Psychiatric Epidemiology (ICPE) Surveys. Int J Methods Psychiatr Res. 2003;12(1):3-21. 4. Kessler RC, Berglund $P$, Demler $O$, Jin R, Merikangas $\mathrm{KR}$, Walters EE. Lifetime prevalence and age-of-onset distributions of DSM-IV disorders in the National Comorbidity Survey Replication. Archives of General Psychiatry. 2005;62(6):593-602.

5. Alhasnawi S, Sadik S, Rasheed $M$, et al. The prevalence and correlates of DSM-IV disorders in the Iraq Mental Health Survey (IMHS). World Psychiatry 2009 June; 8(2): 97-109.

6. Murphy JM, Laird NM, Monson RR, Sobol AM, Leighton $\mathrm{AH}$. A 40-year perspective on the prevalence of depression: The Stirling County Study. Archives of General Psychiatry. 2000;57(3):209-15.

7. Gender differences in unipolar depression: An update of epidemiological findings and possible explanations. Acta Psychiatrica Scandinavica. 2003; 108 (3): 163-74.

8. Alboni P, Favaron E, Paparella N, Sciammarella M, Pedaci $M$. Is there an association between depression and cardiovascular mortality or sudden death?. Journal of cardiovascular medicine (Hagerstown, Md.). 2008; 9 (4): 356-62.

9. Eaton WW, Anthony JC, Gallo J. Natural history of diagnostic interview schedule/DSM-IV major depression. The Baltimore Epidemiologic Catchment Area followup. Archives of General Psychiatry. 1997;54(11):993-99. 10. Mueller TI, Leon AC, Keller MB, et al. Recurrence after recovery from major depressive disorder during 15 years of observational follow-up. Am J Psychiatry. 1999; 156:1000-6.

11. Solomon DA, Keller MB, Leon AC, et al. Multiple recurrences of major depressive disorder. Am J Psychiatry.2000;157:229-33. 
12. Monroe SM. Life stress, the "kindling" hypothesis, and the recurrence of depression: considerations from a life stress perspective. Psychol Rev. 2005;112:417-45.

13. Kendler KS. Stressful life events and previous episodes in the etiology of major depression in women: an evaluation of the "kindling" hypothesis. Am J Psychiatry. 2000;157:1243-51

14. Kendler KS. Genetic risk, number of previous depressive episodes, and stressful life events in predicting the onset of major depression. Am $J$ Psychiatry. 2001;158:582-6.

15. Heim C. Importance of studying the contributions of early adverse experience to neurobiological findings in depression. Neuropsychopharmacology 2004;29:641-8.

16. Keller MB, Lavori PW, Mueller TI, et al. Time to recovery, chronicity, and levels of psychopathology in major depression. A 5-year prospective follow-up of 431 subjects. Arch Gen Psychiatry. 1992;49:809-16.

17. Spijker J, de Graaf R, Bijl RV, Beekman ATF, Ormel $\mathrm{J}$, Nolen WA. Determinants of persistence of major depressive episodes in the general population. Results from the Netherlands Mental Health Survey and Incidence Study (NEMESIS) J Affect Disord. 2004; 81: 231-40.

18. Swanson LW. The hypothalamus. In: Björklund A, editor. Handbook of Chemical Neuroanatomy, Vol. 5, Integrated Systems of the CNS, Part I, Hypothalamus, Hippocampus, Amygdala, Retina. New York, NY: Elsevier; 1987. pp. 1-124.

19. Whittle $S$. The neurobiological basis of temperament: towards a better understanding of psychopathology. Neurosci Biobehav Rev. 2005;30:511-25.

20. MacDonald AW, Cohen JD, Stenger VA, Carter CS. Dissociating the role of the dorsolateral prefrontal and anterior cingulate cortex in cognitive control. Science. 2000; 288:1835-8.

21. Videbech P. Hippocampal volume and depression: a meta-analysis of MRI studies. Am J Psychiatry. 2004; 161:1957-66.

22. Frodl T, M Meisenzahl EM, Zill P, et al. Reduced hippocampal volumes associated with the long variant of the serotonin transporter polymorphism in major depression. Arch Gen Psychiatry. 2004;61:177-83.

23. Frodl T, Schule C, Schmitt G, et al. Association of the brain-derived neurotrophic factor Val66Met polymorphism with reduced hippocampal volumes in major depression. Arch Gen Psychiatry. 2007;64:410-6.

24. Manji HK, Quiroz JA, Sporn J, et al. Enhancing neuronal plasticity and cellular resilience to develop novel, improved therapeutics for difficult-to-treat depression. Biol Psychiatry. 2003;53:707-42.

25. de Kloet ER. Therapy insight: is there an imbalanced response of mineralcorticoid and glucocorticoid receptors in depression. Nat Clin Pract Endocrinol Metab. 2007;3:168-79.
26. Raison CL. Cytokines sing the blues: inflammation and the pathogenesis of depression. Trends Immunol. 2006;27:24-31.

27. Shimizu E, Hashimoto K, Okuma N, et al. Alterations of serum levels of brain-derived neurotrophic factor (BDNF) in depressed patients with or without antidepressants. Biol Psychiatry. 2003;54:70-5.

28. Duman RS. A neurotrophic model for stress-related mood disorders. Biol Psychiatry.2006;59:1116-27.

29. Duman RS. A molecular and cellular theory of depression. Arch Gen Psychiatry. 1997;54:597-606

30. Mayberg HS, Brannan SK, Mahurin RK, et al. Regional metabolic effects of fluoxetine in major depression: serial changes and relationship to clinical response. Biol Psychiatry. 2000;48:830-43.

31. Chen Ridler K, Suckling J CH, Williams $\mathrm{S}$, et al. Brain imaging correlates of depressive symptom severity and predictors of symptom improvement after antidepressant treatment. Biol Psychiatry. 2007;62:40714.

32. O'Brien SM, Scully P, Fitzgerald $P$, et al. Plasma cytokine profiles in depressed patients who fail to respond to selective serotonin reuptake inhibitor therapy. J Psychiatr Res. 2007;41:326-31.

33. Duman RS. Neurotrophic factors and regulation of mood: role of exercise, diet, and metabolism. Neurobiol Aging. 2005;26(Suppl. 1):S88-93.

34. Szádóczky E. Predictors for 2 year outcome of major depressive episode. J Affect Disord.2004;83:49-57.

35. Oswald P, Souery D, Kasper S, et al. Predictive factors of resistance to antidepressant treatment: results from a European multicentre study. Eur Neuropsychopharmacol. 2005;15(Suppl. 3):S326-7.

36. Trivedi MH, Fava M, Marangell LB, et al. Use of treatment algorithms for depression. Prim Care Companion J Clin Psychiatry. 2006;8:291-7.

37. Bair MJ. Depression and pain comorbidity: a literature review. Arch Intern Med. 2003;163:2433-45.

38. Karp JF, Scott J, Houck $P$, et al. Pain predicts longer time to remission during treatment of recurrent depression. J Clin Psychiatry. 2005;66:591-7.

39. Fava M, Mallinckrodt CH, Detke MJ, et al. The effect of duloxetine on painful physical symptoms in depressed patients: do improvements in these symptoms result in higher remission rates. J Clin Psychiatry. 2004;65:52130.

40. Pintor L, Gastó C, Navarro V, et al. Relapse of major depression after complete and partial remission during a 2-year follow-up. J Affect Disord. 2003;73:237-44. 